\title{
Probability analysis for prediction of annual maximum rainfall of one to five consecutive months for Sultanpur region
}

\author{
Anurag Patel ${ }^{1 *}$ and Raj Kumar Verma \\ Vaugh Institute of Agricultural Engineering and Technology (SHUATS), Allahabad (U.P.) India \\ (Email: 3679anuragpatel@gmail.com)
}

\begin{abstract}
The present study was conducted for probability analysis of $17^{\text {th }}$ years (1994-2010) with the prime objective for prediction of annual maximum rainfall of one to five consecutive months Sultanpur region. The maximum rainfall values were estimated by proposed prediction models viz., Gumbel, Log Pearson Type III and Log Normal. The predicted values were compared with observed values and correlation between the predicted and observed values was also established. Rainfall data had been in the above distributions and their corresponding rainfall events were estimated at 5.5, 11.5, 6.6, 33.3 and 50 per cent probabilities level. The goodness of fit models was tested by chi-square. The comparison between the measured and predicted maximum value of rainfall clearly shows that the developed model can be efficiently used for the prediction of rainfall. The statistical comparison by chi-square test for goodness of fit clearly indicates that the Gumbel distribution was found to be best model for predicting two, three, four and five consecutive months annual maximum rainfalls ( $\mathrm{mm}$ ) while Log Pearson types III are fairly close to observed for one and four consecutive months annual maximum rainfall (mm). Rainfall prediction by Log Normal distribution shows very close relation to the observed rainfall for one consecutive months annual maximum rainfall (mm).
\end{abstract}

Key Words : Probability analysis, Prediction, Annual maximum rainfall

View Point Article : Patel, Anurag and Verma, Raj Kumar (2019). Probability analysis for prediction of annual maximum rainfall of one to five consecutive months for Sultanpur region. Internat. J. agric. Sci., 15 (1) : 15-24, DOI:10.15740/HAS/IJAS/15.1/15-24. Copyright@ 2019: Hind Agri-Horticultural Society.

Article History : Received : 11.07.2018; Revised : 16.11.2018; Accepted : 22.11.2018

\footnotetext{
*Author for correspondence: (Present Address)

${ }^{1}$ Central Institute of Agricultural Engineering, Nabibagh, Bhopal (M.P.) India
} 